\title{
Biedronki (Coleoptera: Coccinellidae) odłowione przy użyciu samołówek świetlnych w trzech kompleksach leśnych we wschodniej i centralnej Polsce
}

\author{
Ladybird Beetles (Coleoptera: Coccinellidae) Attracted to Light in Three Forest Complexes \\ in Eastern and Central Poland
}

\author{
Przemysław Kamiński ${ }^{1}$, Sebastian Tobiasz ${ }^{1}$, Małgorzata Grochowska ${ }^{2}$, Artur Baranowski ${ }^{2}$, \\ Jerzy Romanowski ${ }^{2}$, Piotr Ceryngier ${ }^{2 *}$ \\ ${ }^{1}$ Wydział Biologii i Nauk o Środowisku, Uniwersytet Kardynała Stefana Wyszyńskiego w Warszawie \\ ${ }^{2}$ Instytut Nauk Biologicznych, Uniwersytet Kardynała Stefana Wyszyńskiego w Warszawie \\ ORCID: PK https://www.orcid.org/0000-0003-1265-4266; ST https://www.orcid.org/0000-0002-6703-4868; \\ MG https://www.orcid.org/0000-0001-7516-9896; AB https://www.orcid.org/0000-0003-1543-8251; \\ JR https://www.orcid.org/0000-0003-1050-6403; PC https://www.orcid.org/0000-0003-1085-9751 \\ * p.ceryngier@uksw.edu.pl \\ Zgłoszono: 20.02.2020; zrecenzowano: 1.04.2020; zaakceptowano do druku: 6.04.2020
}

\begin{abstract}
Streszczenie: Chrząszcze z rodziny biedronkowatych (Coccinellidae), jako ważny czynnik ograniczający liczebność stawonogów powodujących szkody w uprawach, są częstym obiektem badań entomologicznych. Do odłowów stosuje się różne metody, przy czym do rzadziej wykorzystywanych należy metoda przywabiania chrząszczy do światła. W niniejszych badaniach zastosowaliśmy tę metodę do odłowu biedronek w rezerwacie Jata k. kukowa oraz w dwóch kompleksach leśnych położonych w granicach administracyjnych Warszawy: w rezerwacie Las Bielański i w Lesie Młocińskim. Nocne odłowy owadów do samołówek świetlnych prowadzono w latach 2018 i 2019 między marcem a listopadem, jednak biedronki wpadały do pułapek w okresie od kwietnia do września. Łącznie na trzech stanowiskach odłowiono 347 osobników Coccinellidae należących do 16 gatunków. Największe bogactwo gatunkowe (15 gatunków), a jednocześnie najmniejszą średnią liczebność biedronek (1,3 osobnika na próbę) odnotowano w Jacie. W Lesie Bielańskim stwierdzono 9 gatunków i średnio 4 osobniki na próbę, a w Lesie Młocińskim 4 gatunki i średnio 2,2 osobnika na próbę. Na wszystkich trzech stanowiskach gatunkiem dominującym była Calvia decemguttata (L.). Wysoki udział miały również Harmonia axyridis (Pallas) i Vibidia duodecimguttata (Poda). Większość odłowionych osobników biedronek (71\%) należała do gatunków pozbawionych ubarwienia ostrzegawczego, co może pośrednio świadczyć o ich nocnym trybie życia.
\end{abstract}

Słowa kluczowe: Coccinellidae, Calvia decemguttata, Harmonia axyridis, Vibidia duodecimguttata, aktywność nocna

\footnotetext{
Abstract: As an important limiting factor of arthropods harmful to crop plants, ladybird beetles (Coccinellidae) are a frequent subject of entomological research. Various methods have been used to collect them but attracting them via the use of light has rarely been applied. In this study, we used this method to catch ladybirds in the Jata nature reserve (Eastern Poland), and in two forest complexes within the administrative boundaries of Warsaw (Central Poland), namely, the Bielański forest nature reserve, and the Młociński forest. Night catches of ladybirds into light traps took place from April to September in both 2018 and 2019. Altogether, 347 ladybirds belonging to 16 species were collected. The highest ladybird species richness, amounted to 15 species, but also the lowest mean number of ladybird individuals (1.3 per sample) were recorded in Jata. In the Bielański forest, nine species and the average of 4 individuals per sample were
} 
recorded, whilst in the Młociński forest, the respective values were four species, and 2.2 individuals per sample. In all three localities, Calvia decemguttata (L.) prevailed. Other species with a relatively high contribution were Harmonia axyridis (Pallas) and Vibidia duodecimguttata (Poda). The majority of the sampled ladybird individuals (71\%) belonged to the species having no warning colouration, which may indirectly indicate their nocturnal lifestyle.

Keywords: Coccinellidae, Calvia decemguttata, Harmonia axyridis, Vibidia duodecimguttata, nocturnal activity

\section{Wstęp}

Większość chrząszczy z rodziny Coccinellidae to drapieżniki mszyc, czerwców, przędziorków i innych stawonogów mogących powodować szkody w uprawach (Obrycki, and Kring 1998; Hodek, and Evans 2012). Biedronki, będąc ważnym czynnikiem ograniczającym liczebność tych niepożądanych z punktu widzenia człowieka stawonogów, są też popularnym obiektem badań prowadzonych przez entomologów, jak również specjalistów w zakresie nauk rolniczych i leśnych, czy biologicznego zwalczania (Obrycki, and Kring 1998). Jako owady bytujące zwykle na roślinach biedronki łowi się najczęściej przy pomocy czerpaka entomologicznego (warstwa zielna) lub otrząsa z gałęzi na tzw. parasol entomologiczny (drzewa i krzewy). Dobre wyniki dają również odłowy w żółte miski (pułapki Moerickego) ustawione na ziemi lub blisko niej, bądź zawieszone w koronach drzew. Do metod uzupełniających można zaliczyć pułapki Malaise'a i Barbera (Samways, McGeoch, and New 2010; Honěk 2012). Przywabianie do światła, dobrze sprawdzające się przy odłowach owadów o nocnym trybie życia, rzadko jest stosowane do rejestracji biedronek (Honěk 1977; van Wielink 2017a; van Wielink 2017b). Jako metoda selektywna umożliwiająca wykazanie tylko niektórych występujących na badanym obszarze gatunków, przywabianie do światła ma pod pewnymi względami przewagę nad innymi metodami: pozwala wyróżnić gatunki o aktywności nocnej oraz umożliwia odłowy tych, które występują w środowiskach trudno dla badacza dostępnych, np. w koronach drzew. Skuteczność metody przywabiania do światła może być wysoka, ze względu na znaczne odległości, z których zlatują się owady (Samways, McGeoch, and New 2010). W niniejszym artykule przedstawione zostały dane dotyczące biedronek odłowionych do samołówek świetlnych w trzech kompleksach leśnych: dwóch usytuowanych w granicach administracyjnych Warszawy i jednym pozamiejskim.

\section{Teren badań}

Odłowy owadów prowadzono w rezerwacie przyrody Jata koło Łukowa (strefa UTM 34U, kwadrat EC85) oraz w dwóch kompleksach leśnych położonych w granicach Warszawy: w rezerwacie przyrody Las Bielański (34U, DC99) i w Lesie Młocińskim (34U, DC99).

Rezerwat Jata leży ok. $5 \mathrm{~km}$ na zachód od Łukowa. Głównym przedmiotem ochrony są w nim lasy ze znaczącym udziałem jodły pospolitej (Abies alba), która ma tu izolowane, najdalej na północny wschód wysunięte europejskie stanowisko. Ze względu na wielką wartość naukową tego kompleksu leśnego został on objęty ochroną rezerwatową już w 1933 r. (Stanicka 2010). Rezerwat Jata podlega również ochronie w ramach sieci $\mathrm{Na-}$ tura 200o, wchodząc w skład specjalnego obszaru ochrony siedlisk PLHo60108.

Położony w północno-zachodniej części Warszawy Las Bielański jest jednym z nielicznych lasów w Polsce, gdzie na znacznych obszarach nigdy nie prowadzono zrębów zupełnych, dzięki czemu utrzymana tam została ciągłość trwania zespołów leśnych. Do najlepiej zachowanych zbiorowisk roślinnych należą tutaj łęgi jesionowo-wiązowe oraz lasy dębowo-grabowe (grądy). Od 1973 r. większa część Lasu Bielańskiego podlega 
ochronie rezerwatowej (Chojnacki, Luniak, i Miścicki 2013). Ustanowiono specjalny obszar ochrony siedlisk (PLH140041) o granicach mających zbliżony przebieg do granic rezerwatu.

Leżący na północno-zachodnich obrzeżach Warszawy Las Młociński składa się głównie z porastających pagóry wydmowe sztucznych nasadzeń sosny zwyczajnej (Pinus sylvestris) (Chojnacki, i Kozłowska 2013). Od południa przylega do cmentarza na Wólce Węglowej, od zachodu zaś łączy się z dużym kompleksem Puszczy Kampinoskiej.

\section{Metody}

Do odłowów owadów używano samołówek świetlnych z żarówkami rtęciowo-żarowymi typu MIX 250W. Próby pobierano w latach 2018 i 2019 , od marca do listopada, z częstotliwością 1-2 razy na 10 dni. Pułapki standardowo umieszczano w warstwie podszytu, jednak w 2018 r. w Lesie
Bielańskim jedną samołówkę umieszczono również w warstwie koron drzew, na wysokości $21 \mathrm{~m}$. Odłowy prowadzono zawsze od zmierzchu do świtu. Wpadające do pułapek owady usypiano oparami tetrachloroetylenu. Ogółem w ciągu dwóch lat badań w rezerwacie Jata pobrano 118 całonocnych prób, w rezerwacie Las Bielański - 64 próby, a w Lesie Młocińskim - 29 prób. Ponieważ jednak w próbach pobieranych na początku i pod koniec sezonu nie stwierdzano przedstawicieli rodziny Coccinellidae, przy obliczeniach średniej liczebności biedronek na próbę uwzględniono jedynie próby pobierane w okresie aktywności biedronek, tzn. od drugiej dekady kwietnia do trzeciej dekady września. W tym przedziale czasowym, w ciągu dwóch lat pobrano w Jacie 92 próby, w Lesie Bielańskim - 46 prób, a w Lesie Młocińskim - 21 prób.

Zezwolenia na prowadzenie badań na stanowiskach objętych ochroną rezerwatową zostały wydane przez Regionalną Dyrekcję

Tabela 1. Skład gatunkowy Coccinellidae odłowionych do samołówek świetlnych w rezerwacie Jata (Jata), w rezerwacie Las Bielański (LB) i w Lesie Młocińskim (LM) w latach 2018 i 2019

Table 1. Species composition of Coccinellidae caught into light traps in Jata nature reserve (Jata), Las Bielański nature reserve (LB) and Las Młociński (LM) in 2018 and 2019

\begin{tabular}{|c|c|c|c|c|c|c|c|}
\hline \multirow[t]{2}{*}{ Gatunek } & \multicolumn{2}{|c|}{ Jata } & \multicolumn{2}{|c|}{ LB } & \multicolumn{2}{|c|}{ LM } & \multirow{2}{*}{ Łącznie } \\
\hline & 2018 & 2019 & 2018 & 2019 & 2018 & 2019 & \\
\hline Adalia bipunctata (L.) & - & 1 & - & - & - & - & 1 \\
\hline Adalia decempunctata (L.) & 2 & 1 & 4 & 2 & 1 & - & 10 \\
\hline Anatis ocellata (L.) & 3 & 2 & - & 1 & - & - & 6 \\
\hline Calvia decemguttata (L.) & 16 & 41 & 42 & 35 & 12 & 19 & 165 \\
\hline Calvia quatuordecimguttata (L.) & 1 & 2 & 3 & 2 & - & - & 8 \\
\hline Calvia quindecimguttata (Fabricius) & - & 1 & - & - & - & - & 1 \\
\hline Chilocorus renipustulatus (Scriba) & 1 & - & - & - & - & - & 1 \\
\hline Coccinella septempunctata L. & - & - & 1 & - & - & - & 1 \\
\hline Halyzia sedecimguttata (L.) & 5 & - & 2 & - & - & - & 7 \\
\hline Harmonia axyridis (Pallas) & 5 & 25 & 38 & 2 & 3 & 5 & 78 \\
\hline Hippodamia tredecimpunctata (L.) & - & 3 & - & - & - & - & 3 \\
\hline Myrrha octodecimguttata (L.) & 2 & - & - & 1 & - & - & 3 \\
\hline Propylea quatuordecimpunctata (L.) & - & 1 & - & - & - & - & 1 \\
\hline Psyllobora vigintiduopunctata (L.) & - & 1 & - & - & - & - & 1 \\
\hline Sospita vigintiguttata (L.) & 1 & 1 & - & - & - & - & 2 \\
\hline Vibidia duodecimguttata (Poda) & - & 2 & 35 & 16 & 2 & 4 & 59 \\
\hline Łącznie & 36 & 81 & 125 & 59 & 18 & 28 & 347 \\
\hline
\end{tabular}


Ochrony Środowiska w Warszawie (Las Bielański, WPN I.6205.39.2018.SB) oraz Lublinie (Jata, WPN.6205.1.4.2018.MO).

\section{Wyniki}

W obu latach badań, na trzech stanowiskach odłowiono łącznie 347 osobników Coccinellidae należących do 16 gatunków. Prawie połowa z nich (165 osobników, 48\%) należała do gatunku Calvia decemguttata (L.). Dwa następne pod względem liczebności gatunki to Harmonia axyridis (Pallas) (78 osobników, 22\%) i Vibidia duodecimguttata (Poda) (59 osobników, 17\%). Całkowite liczebności pozostałych zarejestrowanych gatunków nie przekraczały 10 osobników (tabela 1).

Spośród trzech stanowisk badawczych, największe bogactwo gatunkowe Coccinellidae zostało zarejestrowane $\mathrm{w}$ rezerwacie Jata. Stwierdzono w nim 15 gatunków, podczas gdy w Lesie Bielańskim - 9, a w Lesie Młocińskim tylko 4.

Najwięcej osobników biedronek odłowiono w Lesie Bielańskim (184), nieco mniej w Jacie (117), a najmniej w Lesie Młocińskim (46). Średnia liczebność biedronek na próbę była najwyższa w Lesie Bielańskim (4 osobniki na próbę), niższa w Lesie Młocińskim $(2,2$ osobnika na próbę), a najniższa w Jacie ( 1,3 osobnika na próbę).

Na wszystkich trzech stanowiskach gatunkiem dominującym była $C$. decemguttata. Jej udział wśród ogółu odłowionych Coccinellidae wyniósł w Lesie Bielańskim 42\%, w Jacie $-49 \%$, a w Lesie Młocińskim - 67\%.

\section{Dyskusja}

Z trzech uwzględnionych w niniejszej pracy stanowisk, jedynie w Lesie Bielańskim zbierane były wcześniej dane dotyczące fauny Coccinellidae. Na początku lat 5o. ubiegłego wieku systematyczne odłowy biedronek prowadził tu Bielawski (1961), a w latach 2007 i 2009 próby pobierała K. Ciesielska, gromadząc materiały do prac dyplomowych (inżynierskiej i magisterskiej) (omówienie tych prac - patrz Ceryngier 2011). Bielawski wykazał obecność w Lesie Bielańskim
33 gatunków Coccinellidae, Ciesielska zaś 25 gatunków, w tym 8 niestwierdzonych wcześniej przez Bielawskiego. Łącznie więc w kompleksie Lasu Bielańskiego odnotowali aż 41 gatunków biedronek. Niniejsze badania nie wniosły do tego wykazu żadnego nowego gatunku - wszystkie zarejestrowane przez nas gatunki były wcześniej wykazane przez Bielawskiego i/lub Ciesielską.

Choć, jak dotąd, brak było opublikowanych danych na temat fauny biedronek Lasu Młocińskiego, w kilku pracach uwzględnione zostały tereny bezpośrednio do niego przylegające. Na sąsiadującym z Lasem od południa Cmentarzu Komunalnym Północnym na Wólce Węglowej (Romanowski, Ptaszyński, i Ceryngier 2019) stwierdzili 31 gatunków Coccinellidae, a w Parku Młocińskim, będącym przedłużeniem Lasu od strony wschodniej, K. Bodzon i P. Ceryngier (2016) wykazali obecność 20 gatunków. Ponadto, wycinkowe dane o biedronkach odłowionych w dolinie Wisły na wysokości Młocin znaleźć można w innych pracach (Ceryngier, and Godeau 2013; Ceryngier et al. 2017). Łącznie, w otoczeniu Lasu Młocińskiego zostało stwierdzonych 37 gatunków biedronek, w tym wszystkie 4 zarejestrowane podczas niniejszych badań.

Odłowy przeprowadzone w rezerwacie Jata dostarczyły pierwszych, jak się wydaje, danych faunistycznych o Coccinellidae tego obszaru. Większość z 15 odnotowanych tu gatunków występuje pospolicie w całym kraju. Do rzadszych w Polsce należą Calvia quindecimguttata (Fabricius), Sospita vigintiguttata (L.) i Vibidia duodecimguttata (Poda). Dwa pierwsze są specjalistami środowiskowymi związanymi z bagiennymi lasami olszowymi, gdzie występują głównie na olszy czarnej (Alnus glutinosa) (Florek, Tragarz, and Ceryngier 2011). Trzeci (V. duodecimguttata) również preferuje środowiska stosunkowo wilgotne, odżywiając się pasożytującymi na różnych roślinach grzybami z rzędu mączniaków (Ascomycetes: Erysiphales). Do niedawna $V$. duodecimguttata uznawana była w Polsce za rzadkość faunistyczną (Bielawski 1959; Stebnicka 1972; 
Burakowski, Mroczkowski, i Stefańska 1986; Ruta, et al. 2009), od pewnego jednak czasu stała się w niektórych regionach kraju pospolita. Tak jest na przykład w zachodniej części Pojezierza Pomorskiego (Cedyński Park Krajobrazowy) (Ceryngier, Romanowski, i Romanowski 2016a) oraz na Mazowszu (Ceryngier, and Godeau 2013; Bodzon, and Ceryngier 2016; Ceryngier, Romanowski, i Romanowski 2016b; Kozon, Romanowski, i Ceryngier 2016; Ceryngier, et al. 2017). Z kolei w północno-wschodniej Polsce nadal jest gatunkiem rzadko odławianym (Ceryngier, Krzysztofiak, i Romanowski 2016; Ceryngier, i Romanowski 2019), a we wschodniej części Pobrzeża Bałtyku, mimo usilnych poszukiwań, nie udało jej się w ostatnich latach odnaleźć (Szawaryn, Ceryngier, i Romanowski 2018). W materiale zebranym w Jacie udział $V$. duodecimguttata wśród odłowionych biedronek był niski ( 2 osobniki, 1,7\% biedronek z tego stanowiska), znacznie niższy od udziału tego gatunku w Lesie Bielańskim (51 osobników, 28\%) i Lesie Młocińskim (6 osobników, 13\%). Wydaje się więc, że rezerwat Jata, w przeciwieństwie do obu stanowisk warszawskich, leży w regionie, w którym $V$. duodecimguttata nie jest zbyt liczna.

Znamienne jest to, że na każdym z przebadanych stanowisk wyraźnym dominantem wśród odłowionych Coccinellidae była Calvia decemguttata. Jest to gatunek niezbyt częsty w Polsce (Bielawski 1959; Burakowski, Mroczkowski, i Stefańska 1986) i w Europie Środkowej (Nedvěd 2015), ale najwyraźniej chętnie przylatujący do źródeł sztucznego światła, o czym wspominają prace (Stebnicka 1972; Burakowski, Mroczkowski, i Stefańska 1986). Wieloletnie badania nad owadami przywabianymi do światła w rezerwacie De Kaaistoep na południu Holandii wykazały, że w latach 1997-2002 C. decemguttata była wśród odławianych w ten sposób biedronek wyraźnym dominantem. Straciła tę pozycję wraz z pojawieniem się w De Kaaistoep (w 2003 r.) inwazyjnej biedronki azjatyckiej (Harmonia axyridis), która stała się zdecydowanie najliczniej odławianym przedstawicielem rodziny Coccinellidae (van Wielink 2017a; van Wielink 2017b). Choć w naszych badaniach $H$. axyridis była rzadsza niż $C$. decemguttata, to należała jednak do owadów często przylatujących w nocy do źródeł światła. Wcześniej, liczne przylatywanie $H$. axyridis do lamp świecących na tarasie budynku odnotowano w Chorwacji (Ceryngier, et al. 2013). Z badań przeprowadzonych w Stanach Zjednoczonych (Koch, and Hutchison 2003; Nalepa 2013) wynika, że $H$. axyridis jest również licznie przywabiana do lamp emitujących promieniowanie ultrafioletowe (tzw. blacklight traps).

Wiele chrząszczy z rodziny Coccinellidae charakteryzuje się wyrazistym ubarwieniem, na które składa się czerwone, pomarańczowe lub żółte tło i kontrastujące z nim czarne plamy. Czasem proporcje jasnych i ciemnych powierzchni są odwrócone na czarnym tle występuje deseń złożony z czerwonych, pomarańczowych lub żółtych plam. Takie rzucające się w oczy ubarwienie, nazywane ubarwieniem ostrzegawczym (aposematycznym), jest sygnałem dla potencjalnych drapieżców, że noszącego je zwierzęcia nie warto atakować, gdyż jest jadowite, ma właściwości toksyczne, albo co najmniej jest niesmaczne (Ceryngier, Roy, and Poland 2012). Większość biedronek odłowionych w niniejszych badaniach pozbawiona jest ubarwienia ostrzegawczego - na tle w różnych odcieniach brązu znajdują się u nich białawe, kremowe lub żółtawe plamy. W ten sposób ubarwione są trzy gatunki z rodzaju Calvia, Halyzia sedecimguttata, Myrrha octodecimguttata, Sospita vigintiguttata i Vibidia duodecimguttata. Łącznie przedstawiciele tych gatunków stanowią 71\% osobników odłowionych w niniejszych badaniach (245 na ogólną liczbę 347). Można więc wysunąć hipotezę, że brak ubarwienia ostrzegawczego jest $u$ nich przystosowaniem do nocnego trybu życia; nie warto inwestować w kosztowną energetycznie produkcję i akumulację barwników, skoro byłyby one słabym ostrzeżeniem dla polujących nocą drapieżników. 


\section{Bibliografia}

Bielawski, Ryszard. 1959. „Chrząszcze - Coleoptera, Biedronki - Coccinellidae." Klucze do Oznaczania Owadów Polski 19: 76.

Bielawski, Ryszard. 1961. „Coccinellidae (Coleoptera) w zbiorowisku roślin zielnych i młodnika sosnowego w Warszawie na Bielanach." Fragmenta Faunistica 8: 485-525.

Bodzon, Karolina, and Piotr Ceryngier. 2016. „Winter and early spring assemblages of ladybird beetles (Coleoptera: Coccinellidae) in two forest habitats in suburban area of Warsaw, central Poland." Studia Ecologiae et Bioethicae 14 (3): 115-129.

Burakowski, Bolesław, Maciej Mroczkowski, i Janina Stefańska. 1986. „Chrząszcze - Coleoptera. Cucujoidea, część 2." Katalog Fauny Polski 23: 13.

Ceryngier, Piotr, Jerzy Romanowski, Justyna Szymańska, Maja Galanciak, Marta Bardzińska, and Mateusz Romanowski. 2013. „Population of the invasive harlequin ladybird Harmonia axyridis (Coleoptera: Coccinellidae) from Pelješac Peninsula, southern Croatia." Studia Ecologiae et Bioethicae 11 (4): 79-91.

Ceryngier, Piotr, and Jean-François Godeau. 2013. "Predominance of Vibidia duodecimguttata (Poda, 1761) in the assemblages of ladybird beetles (Coleoptera: Coccinellidae) overwintering in floodplain forests." Baltic Journal of Coleopterology 13: 41-50.

Ceryngier, Piotr, Anna Krzysztofiak, i Jerzy Romanowski. 2016. „Nowe dane o biedronkowatych (Coleoptera: Coccinellidae) Wigierskiego Parku Narodowego." Kulon 21: 69-74.

Ceryngier, Piotr, Helen E. Roy, and Remy L. Poland. 2012. „Natural enemies of ladybird beetles”. In Ecology and Behaviour of the Ladybird Beetles (Coccinellidae), edited by Ivo Hodek, Helmut F. van Emden, and Alois Honěk, 375-443. Chichester: Blackwell Publ.

Ceryngier, Piotr, i Jerzy Romanowski. 2019. "Chrząszcze z rodziny biedronkowatych (Coleoptera: Coccinellidae) Mazurskiego Parku Krajobrazowego i okolic." W Mazurski Park Krajobrazowy - różnorodność biologiczna i kulturowa, red. Krzysztof Wittbrodt, i Tomasz Janecki, 72-80. Krutyń: Mazurski Park Krajobrazowy.

Ceryngier, Piotr, Jerzy Romanowski, i Matusz Romanowski. 2016a. „Biedronkowate (Coleoptera: Coccinellidae) Cedyńskiego Parku
Krajobrazowego." Wiadomości Entomologiczne 35: 41-58.

Ceryngier, Piotr, Jerzy Romanowski, i Mateusz Romanowski. 2016b. „Biedronkowate (Coleoptera: Coccinellidae) Parku Skaryszewskiego w Warszawie." W Park Skaryszewski w Warszawie - przyroda i użytkowanie, red. Jerzy Romanowski, 177-186. Warszawa: Wydawnictwo UKSW.

Ceryngier, Piotr, Jerzy Romanowski, Karolina Bodzon, Marta Piotrowska, i Dominika Sitarska. 2017. „Zgrupowania biedronkowatych (Coleoptera: Coccinellidae) tarasu zalewowego Wisły w Warszawie." Kulon 22: 117-123.

Ceryngier, Piotr. 2011. „Historia, dzień dzisiejszy i przyszłość badań entomofaunistycznych w Puszczy Kampinoskiej i Lesie Bielańskim." W Wisła jako warsztat badawczy biologów, red. Piotr Matyjasiak i Jerzy Romanowski, 41-70, Warszawa: Wydawnictwo UKSW.

Chojnacki, Jan, i Anna Kozłowska. 2013. „Główne typy roślinności.” W Przyroda Bielan warszawskich, red. Maciej Luniak, 99-115, Warszawa: Muzeum i Instytut Zoologii PAN.

Chojnacki, Jan, Maciej Luniak, i Stanisław Miścicki. 2013. „Las Bielański.” W Przyroda Bielan warszawskich, red. Maciej Luniak, 211-221. Warszawa: Muzeum i Instytut Zoologii PAN.

Florek, Karolina, Joanna Tragarz, and Piotr Ceryngier. 2011. „Species composition and diets of ladybird beetles (Coleoptera: Coccinellidae) associated with black alder (Alnus glutinosa (L.) Gaertner) in a marshy forest." Aphids and Other Hemipterous Insects 17: 165-174.

Hodek, Ivo, and Edward W. Evans. 2012. „Food relationships." In Ecology and Behaviour of the Ladybird Beetles (Coccinellidae), edited by Ivo Hodek, Helmut F. van Emden, Alois Honěk, 141274. Chichester: Blackwell Publ.

Honěk, Alois. 1977. „Annual variation in the complex of aphid predators: investigation by light trap." Acta Entomologica Bohemoslovaca 74: 345-348. Honěk, Alois. 2012. „Distribution and habitats.” In Ecology and Behaviour of the Ladybird Beetles (Coccinellidae), edited by Ivo Hodek, Helmut F. van Emden, Alois Honěk, 110-140. Chichester: Blackwell Publ.

Koch, Robert L., and William D. Hutchison. 2003. „Phenology and blacklight trapping of the multicolored Asian lady beetle (Coleoptera: 
Coccinellidae) in a Minnesota agricultural landscape." Journal of Entomological Science 38: 477-480.

Kozon, Ewelina, Piotr Ceryngier, i Jerzy Romanowski. 2016. „Zimowanie biedronkowatych (Coleoptera: Coccinellidae) w strefie podmiejskiej Warszawy." Wiadomości Entomologiczne 35: 82-90.

Nalepa, Christine A. 2013. „Coccinellidae captured in blacklight traps: Seasonal and diel pattern of the dominant species Harmonia axyridis (Coleoptera: Coccinellidae)." European Journal of Entomology 110: 593-597.

Nedvěd, Oldřich. 2015. Brouci čeledi slunéčkovití (Coccinellidae) středni Evropy / Ladybird beetles (Coccinellidae) of Central Europe. Praha: Academia.

Obrycki, John J., and Timothy J. Kring. 1998. „Predaceous Coccinellidae in biological control." Annual Review of Entomology 43: 295-321.

Romanowski, Jerzy, Marcin Ptaszyński, i Piotr Ceryngier. 2019. „Biedronkowate (Coleoptera: Coccinellidae) Cmentarza Północnego w Warszawie." Przeglad Przyrodniczy 30(1): 59-65.

Ruta, Rafał, Paweł Jałoszyński, Szymon Konwerski, Tomasz Majewski, i Tomasz Barłożek. 2009. „Biedronkowate (Coleoptera: Coccinellidae) Polski.
Część 1. Nowe dane faunistyczne." Wiadomości Entomologiczne 28: 91-112.

Samways, Michael J., Melodie A. McGeoch, and Tim R. New. 2010. Insect Conservation: A Handbook of Approaches and Methods. Oxford: Oxford University Press.

Stanicka, Małgorzata. 2010. „Rozwój sieci rezerwatów przyrody na Lubelszczyźnie.” Annales Universitatis Mariae Curie-Skłodowska, Sectio B 65: 117-136.

Stebnicka, Zdzisława. 1972. „Coccinellidae (Coleoptera) okolic Krakowa." Acta Zoologica Cracoviensia 17: 1-36.

Szawaryn, Karol, Piotr Ceryngier, and Jerzy Romanowski. 2018. „New data on the distribution of ladybird beetles (Coleoptera: Coccinellidae) in the eastern part of the Baltic Coast region in Poland." Fragmenta Faunistica 61: 39-53.

van Wielink, Paul S. 2017a. „Harmonia axyridis (Coleoptera: Coccinellidae): 13 jaar gevolgd met lichtvangsten in De Kaaistoep, Noord-Brabant." Entomologische Berichten 77: 97-105.

van Wielink, Paul S. 2017b. „Negentien jaar lichtvangsten van lieveheersbeestjes in De Kaaistoep (Coleoptera: Coccinellidae)." Entomologische Berichten 77: 127-139. 